Electronic Physician (ISSN: 2008-5842)

http://www.ephysician.ir

March 2018, Volume: 10, Issue: 3, Pages: 6534-6539, DOI: http://dx.doi.org/10.19082/6534

\title{
Antagonistic effect of isolated probiotic bacteria from natural sources against intestinal Escherichia coli pathotypes
}

\author{
Sahar Karimi ${ }^{1}$, Ehsan Rashidian ${ }^{2}$, Mehdi Birjandi ${ }^{3}$, Leila Mahmoodnia ${ }^{4}$
}

${ }^{1}$ M.Sc. of Microbiology, Department of Biology, Faculty of Science, Shahid Chamran University of Ahvaz, Iran

${ }^{2}$ Assistant Professor of Microbiology, Faculty of Veterinary Medicine, Lorestan University, Iran

${ }^{3}$ Assistant Professor of Medical Epidemiology, Razi Herbal Medicines Research Center, School of Health and Nutrition, Lorestan University of Medical Sciences, Khorramabad, Iran

4 Nephrology Fellowship, Department of Internal Medicine, Shahrekord University of Medical Sciences, Shahrekord, Iran

\section{Type of article: Original}

\begin{abstract}
Background: Probiotics are live microorganisms which are beneficial bacteria that are normal flora of the digestive system which, in determined amounts, show beneficial effects on host health, and can balance gastrointestinal microflora. Digestive tract diseases such as diarrhea are one of the major causes of child mortality in developing countries. Different pathotypes of Escherichia coli cause diarrhea that affects children, therefore reduction of these colonization strains in humans or animals can decline gastrointestinal disorders such as diarrhea.

Objective: The aim of this study was to determine the antimicrobial effect of probiotic bacterial strains isolated from different natural sources against 4 pathotypes of pathogenic E. coli using disk and well diffusion methods.

Methods: This cross-sectional study was conducted from December 2013 to July 2014 on Martyr Chamran University in Ahwaz city. A total of 13 probiotic colonies isolated from 20 samples of traditional dairy products including yogurt, cheese and milk, and 20 samples of vegetables including carrots and cabbages (red and white), of which 5 isolates were selected to determine the antimicrobial effect against 4 Escherichia coli pathotypes, randomly. The antimicrobial effect was evaluated using two methods: disk diffusion and well diffusion tests and measuring growth inhibition zones of probiotics against 4 pathotypes of pathogenic $E$. coli.

Results: Obtained results showed growth inhibition effects of all 5 probiotic strains against Escherichia coli pathotypes in both used methods. But in comparison Lactobacillus plantarum had higher growth inhibitory effects in both methods.

Conclusion: results of this study demonstrated high antimicrobial effect of probiotic bacteria against pathogenic Escherichia coli strains. It indicated a positive and beneficial role of probiotics in human health and prevention of illness.
\end{abstract}

Keywords: Probiotics, Antimicrobial effects, Pathogenic strains, Intestinal infections, Escherichia coli

\section{Introduction}

There are many reasons for the relationship between lifestyle and inducing most diseases and infections. In the past centuries, changing in living conditions with reduced physical activity, stresses of modern life, artificial nutrition and a normal life have increased susceptibility to infectious diseases in humans. Widespread use of synthetic antimicrobial agents caused resistance of infectious agents to these compounds (1-3). For this reason, prevention and treatment by natural antimicrobials appear to be essential. One of the vulnerable parts of the body to pathogens, is the digestive system. Different pathotypes of Escherichia coli are common pathogens of gastrointestinal tract diseases $(1,2)$. Use of antibiotics for treatment and prevention of this bacteria not only induces resistance to these

\section{Corresponding author:}

Dr. Leila Mahmoodnia, Department of Internal Medicine, Shahrekord University of Medical Sciences, Shahrekord, Iran. Tel: +989131849752, Fax:+983813330709, Email: leilamahmoodnia@yahoo.com

Received: August 18, 2016, Accepted: December 26, 2016, Published: March 2018

iThenticate screening: November 12, 2016, English editing: February 09, 2017, Quality control: February 15, 2018

(C) 2018 The Authors. This is an open access article under the terms of the Creative Commons Attribution-NonCommercialNoDerivs License, which permits use and distribution in any medium, provided the original work is properly cited, the use is non-commercial and no modifications or adaptations are made. 
compounds, but also causes disturbance of the normal flora of the digestive system leaving the body vulnerable to a variety of intestinal diseases such as diarrhea. Oral consumption of beneficial microorganisms such probiotics as dietary supplement can immunize people against pathogens $(1,4)$. Probiotics are live microorganisms that, in determined amounts, show beneficial effects on host health, and can balance gastrointestinal microflora (5). They promote the growth and balance of useful bacteria, reducing pathogenic microorganisms and therefore reduce gastrointestinal diseases (6). They are found in dry foods and different natural resources, and can be used in the treatment and prevention of many infectious diseases $(2,4)$. In fact, one of the beneficial effects of probiotics is to prevent and reduce gastrointestinal infectious diseases in the host (3). Lactobacillus, Enterococcus, Bifidobacterium, Saccharomyces, Clostridium, and Bacillus are the main genera of probiotics. Several mechanisms are used by probiotics to inhibit growth and multiplication of intestinal pathogens including production of antimicrobial substances, production of organic acids, activation of body's immune system, competition with pathogens in getting food and attachment to host cell's receptors $(2,3)$. E. coli pathotypes are one of these pathogens (7). Digestive tract disease such as diarrhea is one of the major causes of child mortality in developing countries. It's estimated that 3 to 5 million diarrhea cases have resulted in death. Different pathotypes of E. coli cause diarrhea that affect children. These pathotypes are divided into 6 categories based on different attributes (8). Several studies have shown that probiotics can inhibit growth of Staphylococcus aureus, Salmonella spp., Shigella spp., E. coli, Enterobacter spp., Vibrio cholerae and Helicobacter pylori, by competition and prevention of their attachment and colonization to host's intestinal cells, after taking orally $(9,10)$. The aim of this study was to determine the antimicrobial effect of probiotic bacterial strains isolated from different natural sources against 4 pathotypes of pathogenic E. coli using disk and well diffusion methods.

\section{Material and Methods}

\subsection{Isolation and identification of bacteria}

This cross-sectional study was conducted from December 2013 to July 2014 in Ahwaz city. To separate probiotic bacteria, 20 samples of traditional dairy products including yogurt, cheese, milk and 20 samples of vegetables including carrots and cabbages (red and white), were collected in May 2014 from different areas of Ahvaz city as well as 10 samples of Tarkhineh (traditional food rich of variety of specific probiotic) which were collected from Khorramabad (West of Iran). MRS Broth and MRS Agar mediums (Merck, Germany) were used for the separation of prepared samples. At first, $1 \mathrm{~g}$ of each sample (dairy, vegetables, Tarkhineh) were crushed in a sterile mortarand weighed, dissolved in $10 \mathrm{ml}$ MRS Broth medium and incubated at $37^{\circ} \mathrm{C}$, then shaken at $140 \mathrm{rpm}$ for 24 hours (11). Serial dilution was prepared (to $10^{-3}$ ), further purification was performed under sterile conditions by culturing in MRS Agar medium. All isolated colonies were identified using biochemical tests (gram staining, catalase test, oxidase test, growth at different temperatures and carbohydrate fermentations, motility) and molecular assessment (polymerase chain reaction test) (12). General primers were used to perform PCR test (Takapoozist, Iran). Primer's sequencing was shown in Table 1. To confirm genome replication and determine fragment size, PCR protocol was followed on agarose gel. Gel extraction kit was used for extraction of 1500-bp single bands. To determine sequencing, purified genums were sent to the Takapoozist company. The results were arranged using BioEdit software and was evaluated in the National Center for Biotechnology Information (NCBI) website using Blast software. Phylogenetic trees of identified isolates were drawn using mega-4 software.

Table 1. Selected primers for polymerase chain reaction

\begin{tabular}{|l|l|l|}
\hline Primers type & Primers sequences $\left(5^{\prime}\right.$ to $3^{\prime}$ ) & Product size (bp) \\
\hline Forward primer (FP1) & 5'-AGAGTTTGATCATGGCTCAG-3' $^{\prime}$ & 20 bases \\
\hline Reverse primer (RP1) & 5'-TACGGYTACCTTGTTACGACTT-3' $^{\prime}$ 22 bases \\
\hline
\end{tabular}

\subsection{Supernatant preparing of bacteria}

After isolation and molecular identification of isolates, 5 strains of probiotic bacteria were randomly selected. All selected isolates were cultured in MRS Broth, and incubated at $37^{\circ} \mathrm{C}$ for 24 hours to obtain $0.5 \mathrm{McFarland}$ turbidity $\left(1.5 \times 10^{8} \mathrm{cfu} / \mathrm{ml}\right)$. Bacterial supernatant was prepared by centrifuge of isolates culture suspension for 25 min at $4{ }^{\circ} \mathrm{C}$ and $3500 \mathrm{rpm}$. Four pathogenic strains of E. coli including ETEC (Enterotoxigenic E. coli), EAEC (Enteroaggregative E. coli), EIEC (Enteroinvasive E. coli) and EPEC (Enteropathogenic E. coli) were provided of microbiology department of Tarbiat Modares University in Tehran. TSB medium was used for culturing strains at 37 ${ }^{\circ} \mathrm{C}$. 


\subsection{Evaluation of antimicrobial activity of probiotic bacteria}

Mueller-Hinton agar (MHA) was used to investigate antimicrobial activity of isolated probiotic bacteria. For this purpose, inhibitory and antagonistic effects of probiotic bacteria on 4 pathotype of E. coli was determined using two methods: Disk Diffusion Agar and Well Diffusion Agar methods. All tests were repeated twice.

\subsection{Disk Diffusion Agar method}

Sterile blank disks ( $8 \mathrm{~mm}$ diameter) were smeared with supernatant of 5 probiotic bacteria for 5 minutes. In order to dry the disks, they were placed at $37^{\circ} \mathrm{C}$ for 15 minutes. The suspension of pathogenic bacteria was spread on plates containing MHA medium. Impregnated discs with supernatant were placed on MHA with a $2.5 \mathrm{~cm}$ distance. All plates were incubated at $37^{\circ} \mathrm{C}$ and after for 24 hours' growth, inhibition zone of probiotics against pathotypes of $E$. coli were measured by a ruler.

\subsection{Well Diffusion Agar method}

Suspension of pathogen bacteria cultured in TSB were spread on plates containing MHA, then $10 \mu 1$ of each probiotic supernatant was spilled to punched wells in the plates. After incubation at $37{ }^{\circ} \mathrm{C}$ for 24 hours' growth, inhibition zone was measured (13). In comparison, antimicrobial effects of 5 antibiotics on 4 pathotype E. coli were investigated including: nalidixic acid, penicillin, cephalosporin, gentamicin and novobiocin. For this purpose, the suspension of pathogenic bacteria was spread on TSA plates and antibiotic discs were placed with a distance (2.5 $\mathrm{cm}$ ) on them. After incubation at $37^{\circ} \mathrm{C}$ for 24 hours' growth, inhibition zone were measured with a ruler.

\section{Results}

A total of 13 probiotic colonies isolated from samples which 5 isolates were selected to evaluate the antimicrobial effect against 4 E. coli pathotypes, randomly, were subjected to biochemical and molecular identification. Identified probiotics strains were Lactobacillus plantarum, Lactobacillus Gasseri, Enterococcus faecium, Bacillus subtilis, Weissella paramesenteroides (Figure 1). Obtained results showed growth inhibition effects of all 5 probiotic strains against $E$. coli pathotypes in both used methods. Average growth inhibition zone of 5 probiotic strain against $4 E$. coli pathotypes in disk diffusion and well diffusion methods were 9-12 $\mathrm{mm}$ and 6-9 $\mathrm{mm}$, respectively. In comparison, inhibition zones in disk diffusion were considerable. Results of growth inhibition zones of two disk diffusion and well diffusion methods were shown in Tables 2 and 3. Inhibition zone of used antibiotics against 4 pathotypes of $E$. coli was shown in Table 4. Results showed nalidixic acid that is commonly used to treat urinary tract infections, had significant inhibitory effect on the pathotype of ETEC $(18 \mathrm{~mm})$, EIEC $(20 \mathrm{~mm})$, EAEC (20 $\mathrm{mm}$ ), but did not show inhibitory effects against EPEC strains.

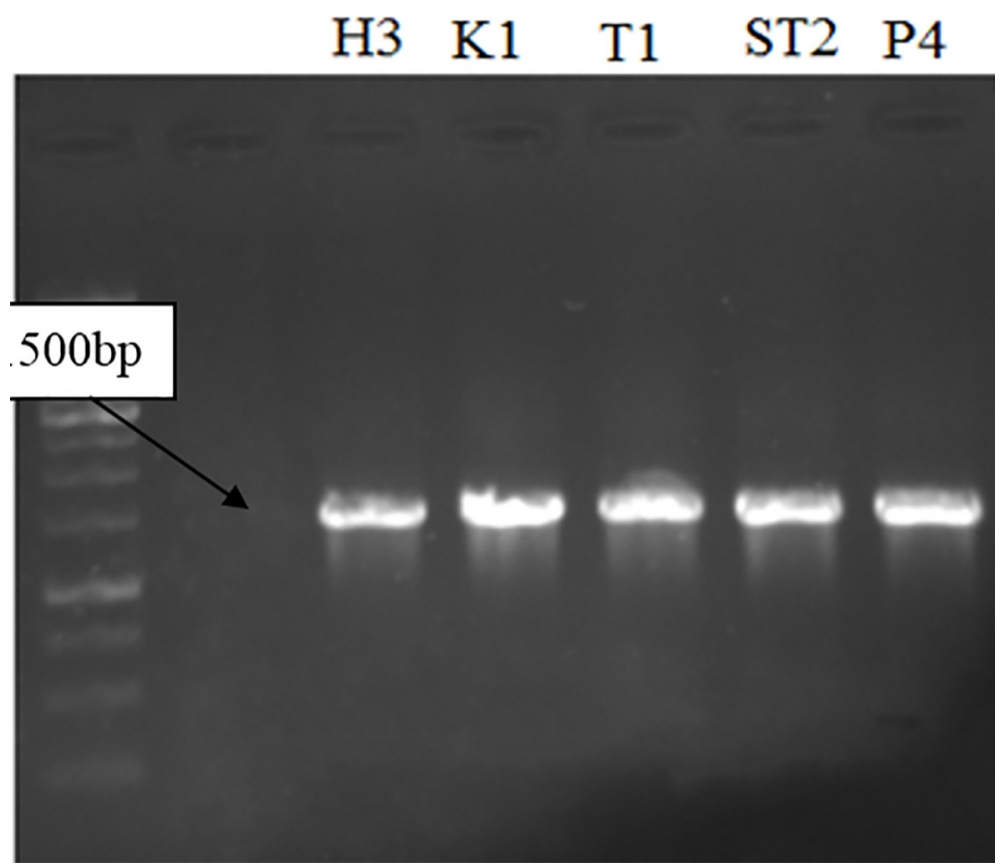

Figure 1. Electrophoresis pattern of PCR products of selected probiotic bacteria 
Table 2. Growth Inhibition zone $(\mathrm{mm})$ of selected probiotic strains against 4 pathotypes of $E$. coli (Disk diffusion method)

\begin{tabular}{|l|l|l|l|l|}
\hline \multirow{2}{*}{ Probiotic } & \multicolumn{3}{l}{ Pathogen } \\
\cline { 2 - 5 } & EAEC & EIEC & ETEC & EPEC \\
\hline L. plantarum & 10 & 9 & 12 & 10 \\
\hline L. gasseri & 9 & 9 & 10 & 9 \\
\hline E. fascium & 10 & 9 & 9 & 9 \\
\hline B. subtilis & - & - & - & 10 \\
\hline W. paramesenteroides & 10 & 9 & 10 & - \\
\hline
\end{tabular}

Table 3. Growth Inhibition zone $(\mathrm{mm})$ of selected probiotic strains against 4 pathotypes of $E$. coli (well diffusion method)

\begin{tabular}{|l|l|l|l|l|}
\hline \multirow{2}{*}{ Probiotic } & \multicolumn{3}{l}{ Pathogen } \\
\cline { 2 - 5 } & EAEC & EIEC & ETEC & EPEC \\
\hline L. plantarum & 7 & 9 & - & 9 \\
\hline L. gasseri & - & - & 6 & - \\
\hline E. fascium & - & - & - & - \\
\hline B. subtilis & 6 & - & - & 9 \\
\hline W. paramesenteroides & 7 & - & - & - \\
\hline
\end{tabular}

Table 4. Growth inhibitory zone of selected antibiotics against 4 pathotypes of E. coli (Antibiogram)

\begin{tabular}{|l|l|l|l|l|}
\hline \multirow{2}{*}{ Antibiotic } & \multicolumn{4}{|l|}{ Pathogen } \\
\cline { 2 - 5 } & EAEC & EIEC & ETEC & EPEC \\
\hline Novobiocin & - & - & - & 10 \\
\hline Penicillin & - & - & - & - \\
\hline Nalidixic acid & 20 & 20 & 18 & - \\
\hline Cephalosporins & - & - & - & - \\
\hline Gentamycin & 15 & - & - & 16 \\
\hline
\end{tabular}

\section{Discussion}

According to obtained results of this study selected probiotics, particularly Lactobacillus strains, had good inhibitory effects against $E$. coli pathotypes. Probiotics such as Lactobacillus genera are natural inhabitants of the intestine that play an important role in human health by avoiding intestinal infection and pathogens elimination. They produce lactic acid and other organic acids that reduce intestinal PH as well as various metabolites to prevent the growth of many pathogenic bacteria (14). In this study, produced metabolites by selected probiotics which were isolated by centrifugation were able to prevent the growth of pathogenic pathotypes of E. coli. Isolated Lactobacilli showed the highest inhibitory effect in both methods. Similar results were obtained in another study. Boris and coworkers showed inhibitory effects of isolated Lactobacilli of dairy products against a range of pathogens (15). Coconnier investigated Lactobacillus acidophilus inhibitory effects against pathogen bacteria (16). In the history of microbiology, most human studies are focused on human and animal pathogenic organisms, while fewer studies are done on beneficial micro-organisms inhabitant in the human body, which causes a poor understanding of internal flora living in the body. The human body is surrounded by a biological system, important microorganisms in or on the body that are human microbiome (17). The human gastrointestinal tract is colonized by various microorganisms which some of these micro-florae are responsible for microbial balance in the host (18). There is co-existence between the host and intestinal microflora (17). The gastrointestinal tract is considered as one of the largest links between the outside environment and the inside of the human body, and animals that use probiotic microorganisms cause beneficial effects on host microflora (19). Probiotics promote the growth of benefits in bacteria and reduce pathogenic microorganisms that result in decline of gastrointestinal diseases. Other beneficial effects of probiotics are anti-allergic effects, anti-cancer, reduction of harmful fats and cholesterol and increasing host immune response (20). It is well established that some intestinal disorders such as irritable bowel syndrome, inflammatory bowel disease and antibiotics caused diarrhea could be more depending on the type of intestinal flora. Probiotics consumption has been recognized as an efficient strategy to deal with these diseases (14).

\section{Conclusions}

At present, with increasing antibiotic resistance and side effects of chemical drugs, an alternative treatment is necessary for this problem. Probiotics and their produced metabolites can be widely used as treatments to various disorders. 


\section{Acknowledgments:}

The authors are thankful to the staff and experts at the Microbiology Laboratory of Veterinary Medicine, Lorestan University who have helped us conduct parts of this research.

\section{Conflict of Interest:}

There is no conflict of interest to be declared.

Authors' contributions:

All authors contributed to this project and article equally. All authors read and approved the final manuscript.

\section{References:}

1) De Roos NM, Katan MB. Effects of probiotic bacteria on diarrhea, lipid metabolism, and carcinogenesis: a review of papers published between 1988 and 1998. Am J Clin Nutr. 2000; 71(2): 405-11. PMID: 10648252 .

2) Leslie CO, Albert B, Max S. Enterobacteriacea. In: Topleyswillsons microbiology and microbial Infections: From Oxford University Inc, NewYork: USA, 514-699; 1998.

3) Fazeli S, Ghasmian H, Mirnzhad R. Reduction of colonization of Enterotoxigenic Escherichia Coli (ETEC) in mice by Probiotic Lactobacillus casei. J Shahrekord Univ Med Sci. 2004; 6(1): 26-33.

4) Gorbach SL. Lactic acid bacteria and human health. Ann Med. 1990; 22(1): 37-41. doi: 10.3109/07853899009147239. PMID: 2109988.

5) Ejtahed H, Mohtadi Nia J, Homayouni Rad A, Niafar M, Asghari Jafarabadi M, Mofid V. The effects of probiotic yoghurt consumption on blood pressure and serum lipids in type 2 diabetic patients: Randomized clinical trial. Journal of Nutrition and Food Technology. 2011; 6(4): 1-12.

6) Shokryazdan P, Sieo CC, Kalavathy R, Liang JB, Alitheen NB, Faseleh Jahromi M, et al. Probiotic potential of Lactobacillus strains with antimicrobial activity against some human pathogenic strains. Biomed Res Int. 2014; 2014: 927268. doi: 10.1155/2014/927268. PMID: 25105147, PMCID: PMC4106073.

7) Hütt P, Shchepetova J, Loivukene K, Kullisaar T, Mikelsaar M. Antagonistic activity of probiotic lactobacilli and bifidobacteria against entero- and uropathogens. J Appl Microbiol. 2006; 100(6): 1324-32. doi: 10.1111/j.1365-2672.2006.02857.x. PMID: 16696680.

8) Kashefiyeh M, Zeighami H, Haghi F. Frequency of Enterotoxigenic Escherichia coli Isolates Harboring eltB and eltA Genes in Diarrheal Specimens among Children Younger than 5 Years in Tabriz Hospitals. Journal of Zanjan University of Medical Sciences. 2013; 21(88): 120-7.

9) Bernet MF, Brassart D, Neeser JR, Servin AL. Lactobacillus acidophilus LA 1 binds to cultured human intestinal cell lines and inhibits cell attachment and cell invasion by enterovirulent bacteria. Gut. 1994; 35(4): 483-9. doi: 10.1136/gut.35.4.483. PMID: 8174985, PMCID: PMC1374796.

10) Spencer RJ, Chesson A. The effect of Lactobacillus spp. on the attachment of enterotoxigenic Escherichia coli to isolated porcine enterocytes. J Appl Bacteriol. 1994; 77(2): 215-20. doi: 10.1111/j.13652672.1994.tb03066.x. PMID: 7961193.

11) Sieladie DV, Zambou NF, Kaktcham PM, Cresci A, Fonteh F. Probiotic properties of lactobacilli strains isolated from raw cow milk in the western highlands of Cameroon. Innovative Romanian Food Biotechnology. 2011; 9: 12.

12) Salaj R, Štofilová J, Šoltesová A, Hertelyová Z, Hijová E, Bertková I, et al. The effects of two Lactobacillus plantarum strains on rat lipid metabolism receiving a high fat diet. The Scientific World Journal. 2013; 2013. doi: 10.1155/2013/135142.

13) Darsanak KR, Ghaemi N, Mirdavoodi F. Anti-mutation activity of probiotic strains isolated from probiotic products. J of Qom Uni of Med Sci. 2012; 6(2): 37-44.

14) Aroutcheva AA, Simoes JA, Faro S. Antimicrobial protein produced by vaginal Lactobacillus acidophilus that inhibits Gardnerella vaginalis. Infect Dis Obstet Gynecol. 2001; 9(1): 33-9. doi: 10.1155/S1064744901000060. PMID: 11368257, PMCID: PMC1784632.

15) Boris S, Jimenez-Diaz R, Caso JL, Barbes C. Partial characterization of a bacteriocin produced by Lactobacillus delbrueckii subsp. lactis U0004. An intestinal isolate with probiotic potential. J Appl Microbiol. 2001; 91(2): 328-33. doi: 10.1046/j.1365-2672.2001.01403.x.

16) Coconnier MH, Lievin V, Hemery E, Servin AL. Antagonistic activity against Helicobacter infection in vitro and in vivo by the human Lactobacillus acidophilus strain LB. Appl Environ Microbiol. 1998; 64(11): 4573-80. PMID: 9797324, PMCID: PMC106686. 
17) Fijan S. Microorganisms with claimed probiotic properties: an overview of recent literature. Int J Environ Res Public Health. 2014; 11(5): 4745-67. doi: 10.3390/ijerph110504745. PMID: 24859749, PMCID: PMC4053917.

18) Tafvizi F, Tajabadi Ebrahimi M, Khojare L. Genotypic and Phylogenic Analysis of Lactobacilli Producing Bacteriocin Isolated from Traditional Dairy Products and Food. J Fasa Univ Med Sci. 2012; 2(2): 84-90.

19) Dafchahi Poramin N. Prebiotics and probiotics in vitro study of cholesterol-lowering impact on the characteristics of probiotic yogurt. Thesis Master of Science in Food Industry. University of Gorgan. 2010.

20) Nsofor $\mathrm{CH}$ A, Sarah CU, Chinyerebibian U. Isolation and characterisation of lactic acid bacteria from ogi sold in elele Nigeria. Journal of Biological and Food Science Research. 2014; 3(2): 19-22. 